\title{
LA FIGURA DEL DELEGADO DEL GOBIERNO EN LAS COMUNIDADES AUTONOMAS
}

por

\author{
Diego Cámara del Portillo
}

SUMARIO: I. INTRODUCCION.-II. ESTATUTO PERSONAL.III. COMPETENCIAS.

\section{INTRODUCCION}

La figura del Delegado del Gobierno en las Comunidades Autónomas, que se crea en el artículo 154 de la Constitución, cuenta en el Derecho patrio con algunos antecedentes históricos, si se consideran como tales los diversos intentos de introducir en nuestra legislación administrativa autoridades estatales con competencia en más de una Provincia.

Así, en 1847 se dividió la Península en once Gobiernos generales. Posteriormente, en el artículo 72.8. del Proyecto de Constitución Federal de la República Española de 1873 se establecía como competencia del Poder ejecutivo la de «enviar a cada Estado regional un Delegado con encargo expreso de vigilar el cumplimiento de la Constitución y de las leyes, de los decretos y reglamentos federales; pero sin autoridad ninguna especial dentro del Estado o del Municipion. En 1884 se crearon quince Gobiernos coincidentes en su ámbito con las Audiencias Territoriales. En 1891 se proyectaron Gobiernos de carácter regional, en los que parecía vislumbrarse 
una incipiente administración regional. En el Estatuto provincial de 1925 se regulaba asimismo la Región con un Gobernador a su cabeza.

Durante la Segunda República se creó la figura de los Delegados especiales por Ley de 1931. El Decreto de 29 de agosto de 1933 creó el cargo de Comisario General de Orden Público en Cataluña, que tenía la condición de Delegado especial del Gobierno en aquella Región.

En el artículo 6. del Estatuto de Cataluña, de 15 de septiembre de 1932, y en el de igual número del Estatuto vasco, de 4 de octubre de 1936, se decía que «el Estado podrá designar en cualquier momento los delegados que estime necesarios para velar por la ejecución de las leyes».

Suspendido, tras los sucesos de octubre de 1934, el Estatuto catalán, fue nombrado un Gobernador general de Cataluña. Otro Gobernador general se nombró también poco después de iniciada nuestra guerra civil por necesidades del momento.

Igualmente existió en nuestro ordenamiento la figura del Gobernador general para las Provincias africanas: la Ley de 19 de abril de 1961, sobre régimen jurídico del Sahara, y el Decreto de 10 de enero de 1958, regulador del régimen jurídico de las Provincias de Ifni y Sahara, preveían la existencia de un Gobernador general; también la Ley de 20 de diciembre de 1963, reguladora del régimen de las Provincias de Fernando Póo y Río Muni, establecía un Gobernador general, aunque para ambas Provincias. En estos supuestos, el Gobernador general recibía esta denominación por ostentar en su territorio tanto el mando civil como el militar.

El Decreto de 10 de octubre de 1958 (derogado por el Real Decreto $3117 / 1980$, de 22 de diciembre, regulador del nuevo Estatuto de los Gobernadores civiles) preveía la creación de la figura del Gobernador civil general en dos supuestos distintos: en el artículo 38, párrafo primero, establecía que «en casos excepcionales, el Jefe del Estado, previa deliberación del Consejo de Ministros, podrá nombrar Gobernadores civiles generales con jurisdicción en el territorio de varias Provincias o parte de ellas»; el artículo 40 añadía que «el nombramiento de Gobernadores civiles generales podrá hacerse también por motivos de orden público, de acuerdo con la legislación especial en la materia, en cuyo caso se limitarán sus atribuciones a este cometido y en tanto subsistan las causas que originaron su designación». Previsión idéntica a esta última aparecía en la Ley 
de Orden Público, donde se hablaba de «Gobernadores civiles generales» encargados especialmente de asegurar el orden público.

El Real Decreto 190/1980, de 1 de febrero, regulador de los. Delegados especiales del Gobierno para la seguridad, confiaba a estos Delegados especiales el mando, coordinación y apoyo logístico de los Cuerpos y Fuerzas de Sguridad del Estado en varias Provincias, ejerciendo, como misión especial, la dirección y planteamiento de la lucha antiterrorista en aquéllas. Por el Real Decreto 192/1980, se designó un Delegado especial del Gobierno para la seguridad en el territorio del País Vasco.

Como hemos indicado más arriba, la figura del Delegado del Gobierno en las Comunidades Autónomas se crea en el artículo 154 de nuestra Constitución, que dice: «un Delegado nombrado por el Gobierno dirigirá la Administración del Estado en el territorio de la Comunidad Autónoma y la coordinará, cuando proceda, con la Administración propia de la Comunidad». Desarrolla este precepto el Real Decreto 2238/1980, de 10 de octubre, por el que se regulan los Delegados del Gobierno en las Comunidades Autónomas, que establece el régimen jurídico de los mismos y sus competencias. No obstante, antes de iniciar el examen de esta disposición creemos conveniente hacer dos precisiones.

La primera de ellas se refiere a los Reales Decretos 190 y 192, de 1 de febrero de 1980, antes citados, reguladores de los Delegados especiales del Gobierno para la seguridad. Entendemos que los mismos han quedado sin efecto en virtud de la cláusula derogatoria que, en sentido genérico, se contiene en la disposición final primera del Real Decreto 2238/1980, regulador de los Delegados del Gobierno en las Comunidades Autónomas, habida cuenta que el artículo 6.2.c) del mismo atribuye a éstos la función de «dirigir y coordinar, en los términos previstos en las leyes y a través de los Gobernadores civiles, la actuación de los Cuerpos y Fuerzas de Seguridad del Estado» en el territorio de la Comunidad Autónoma.

La segunda se refiere al también citado Real Decreto 3117/1980, regulador del Estatuto de los Gobernadores civiles, que deroga expresamente el Decreto de 10 de octubre de 1958. Este Real Decreto no regula, como lo hacía el Decreto que viene a derogar, la figura de los Gobernadores generales, sino que se limita a hacer únicamente una doble referencia a los mismos: de una parte, expresa en su preámbulo que «el reconocimiento constitucional de la Provincia como división territorial para el cumplimiento de los fines del Esta- 
do y el mismo proceso de desarrollo de las Comunidades Autónomas con la efectiva transferencia de funciones y servicios a las ya constituidas, supone una adecuación necesaria de los órganos de la Administración civil del Estado en las Provincias, ya iniciada con la promulgación del Real Decreto 2238/1980, de 10 de octubre, por el que se regulan los Delegados del Gobierno en las Comunidades Autónomas»; de otra, en el artículo 12 dice que el Gobernador civil cuidará de transmitir por vía jerárquica los mandatos y directrices que reciba del Gobierno o, en su caso, de los distintos Departamentos ministeriales, "así como las instrucciones de los Gobernadores generales, en los términos previstos en el Real Decreto dos mil ochocientos (sic) treinta y ocho/mil novecientos ochenta, de diez de octubre».

Hechas estas precisiones, pasamos seguidamente al estudio del Real Decreto 2238/1980, analizando por separado el estatuto personal de la figura del Delegado del Gobierno y las competencias que al mismo se atribuyen.

\section{ESTATUTO PERSONAL}

La denominación de la figura que nos ocupa, pese a ser una cuestión formal, ha suscitado cierta polémica.

Como es sabido, en el artículo 154 de la Constitución se habla de «un Delegado nombrado por el Gobierno». Esta expresión no parece, en principio, impedir al Gobierno la adopción de un término distinto al de «Delegado» empleado en dicho precepto para designar a esta figura. En efecto, en el artículo $10^{\circ}$, párrafo uno, del Real Decreto 2238/1980, se dice que «el Delegado del Gobierno de cada una de las Comunidades Autónomas, previsto en el artículo 154 de la Constitución, recibirá la denominación de Gobernador general». Conforme a ello, reciben esta denominación los primeros Delegados del Gobierno en las Comunidades Autónomas del País Vasco y de Cataluña: Real Decreto 2042/1980, de 10 de octubre, por el que se nombra "Gobernador general» de la Comunidad Autónoma del País Vasco a don Marcelino Oreja Aguirre, y Real Decreto 2213/ 1980 , de 17 de octubre, por el que se nombra «Gobernador general» de Cataluña a don Josep Meliá Pericás.

Dicha denominación, que, como hemos visto, es la que utilizaba el Decreto de 10 de octubre de 1958 para designar a los Goberna- 
dores civiles con jurisdicción sobre varias Provincias o parte de ellas, planteó el problema de su posible inconstitucionalidad.

Quizá por este motivo es posteriormente modificada, en lo que a las Comunidades Autónomas del País Vasco y de Cataluña se refiere, por los Reales Decretos 3184 y 3185, de 22 de diciembre de 1980. El Real Decreto 3184/1980, por el que se establece la estructura orgánica y de personal de los órganos de apoyo de la Delegación del Gobierno en la Comunidad Autónoma del País Vasco, dice en el artículo 7. ${ }^{\circ}$ que «el titular de la Delegación del Gobierno en la Comunidad Autónoma se denominará Delegado general del Gobierno». Igual prescripción se recoge en el artículo 7. del Real Decreto $3185 / 1980$, por el que se establece la estructura orgánica y de personal de los órganos de apoyo de la Delegación del Gobierno en el territorio de la Comunidad Autónoma de Cataluña. Idéntica denominación utilizan los Reales Decretos 742 y 743, de 24 de abril de 1981: por el primero de ellos se dispone cese en el cargo de «Delegado general del Gobierno» en Cataluña don Josep Meliá Pericás, en tanto que por el segundo se nombra «Delegado general del Gobierno» en dicha Región a don Juan Rovira Tarazona.

En lo que respecta a los Delegados del Gobierno en Comunidades Autónomas que no sean las del País Vasco y Cataluña, el problema, por tanto, subsiste, puesto que no parece que puedan ser aplicables a estos supuestos los mencionados Reales Decretos 3184 y 3185 , de 22 de diciembre de 1980, ya que expresamente se refieren a las Comunidades Autónomas del País Vasco y de Cataluña, respectivamente.

Por consiguiente, parece que de no disponerse otra cosa, la denominación de estos Delegados del Gobierno en Comunidades Autónomas que no sean las del País Vasco y Cataluña, debe ser, por aplicación del artículo 1., 1, del Real Decreto 2238/1980, que los regula, la de "Gobernadores generales»; mientras que al ser modificado lo dispuesto en este artículo por los Reales Decretos 3184 y 3185 , de 22 de diciembre de 1980, en lo que se refiere a las Comunidades Autónomas del País Vasco y de Cataluña, los Delegados del Gobierno en estas Comunidades han de denominarse «Delegados generales del Gobierno».

Nos ocuparemos seguidamente de lo relativo al nombramiento y separación de los Delegados del Gobierno en las Comunidades Autónomas. El artículo 2. del Real Decreto 2238/1980 dice que «el Gobernador general será nombrado y separado por Real Decreto, 
acordado en Consejo de Ministros, a propuesta del Presidente del Gobierno".

Así, son acordados en Consejo de Ministros, a propuesta del Presidente del Gobierno, los Reales Decretos 2213/1980, de 17 de octubre, y 742/1981, de 24 de abril, por los que, respectivamente, se dispone el nombramiento y el cese en el cargo de Delegado del Gobierno en Cataluña de don Josep Meliá Pericás. Igualmente es acordado en Consejo de Ministros, a propuesta del Presidente del Gobierno, el Real Decreto 743/1981, de 24 de abril, por el que se nombra Delegado general del Gobierno en Cataluña a don Juan Rovira Tarazona.

Una excepción a lo dispuesto en este artículo $2 .^{\circ}$ del Real Decreto 2238/1980, es el Real Decreto 2042/1980, de 10 de octubre, por el que se nombra Gobernador general de la Comunidad Autónoma del País Vasco a don Marcelino Oreja Aguirre. En efecto, dicho Real Decreto dice: «de conformidad con lo establecido en el artículo 154 de la Constitución, a propuesta del Presidente del Gobierno, vengo a nombrar Gobernador general en la Comunidad Autónoma del País Vasco a don Marcelino Oreja Aguirre, quien tendrá la consideración personal propia de los Ministros». El nombramiento, en este caso, no se efectúa por Real Decreto acordado en Consejo de Ministros, a propuesta del Presidente del Gobierno, sino mediante Real Decreto, a propuesta del Presidente del Gobierno, ya que este último es el procedimiento que se establece en el artículo 100 de la Constitución para el nombramiento de los Ministros.

El tema del nombramiento de los Delegados del Gobierno, como hemos visto, guarda cierta relación con el de su categoría, por lo que nos ocuparemos a continuación del mismo.

El Decreto de 29 de agosto de 1933 atribuía al Comisario general de Orden Público en Cataluña categoría de Jefe superior de Administración civil. El Decreto de 10 de octubre de 1958, al regular la figura del Gobernador general (art. 38, párrafo segundo), se remitía al Decreto de nombramiento en lo relativo a sus atribuciones, las circunstancias relativas al carácter de su designación, el ámbito de la jurisdicción a su mando y su régimen jurídico. Sin embargo, es factible presumir que habrían de tener categoría no inferior, cuando menos, a la de los Gobernadores civiles de Madrid y Barcelona, los cuales la tienen de Subsecretarios (art. 6.').

Nada se dice sobre la categoría de los Delegados del Gobierno en las Comunidades Autónomas en el Real Decreto 2238/1980, que 
los regula, el cual ni siquiera se remite al Decreto de nombramiento. No obstante, habida cuenta de que en el artículo 6. del Real Decreto $3117 / 1980$, regulador del nuevo Estatuto de los Gobernadores civiles, se atribuye también categoría de Subsecretarios a los Gobernadores civiles de Madrid y Barcelona, parece que, por lo menos, los Delegados del Gobierno habrán de tener categoría no inferior a ésta.

Como hemos visto anteriormente, el Real Decreto 2042/1980 atribuye al Gobernador general del País Vasco, don Marcelino Oreja Aguirre, "la consideración personal propia de los Ministros». En cambio, no se da esta categoría al Gobernador general de Cataluña en el Real Decreto 2213/1980, ni tampoco en el Real Decreto $743 / 1981$, en los que ni siquiera se alude a esta cuestión.

En cuanto al tema de las incompatibilidades, el artículo $3 .^{\circ}, 1$, del Real Decreto 2238/1980, dice que «el Gobernador general no podrá ejercer ninguna función pública que no derive de su cargo, ni actividad profesional o mercantil alguna».

Respecto del primer inciso de este artículo, que prohíbe al Delegado del Gobierno el ejercicio de ninguna función pública que no derive de su cargo, se ha suscitado recientemente un problema. En efecto, se ha planteado el asunto de si el cargo de Delegado del Gobierno es o no compatible con el de Diputado al Congreso.

El Congreso de los Diputados al evacuar una consulta sobre este tema ha manifestado que no se da en dicho supuesto una causa de incompatibilidad, sino una causa de inelegibilidad. Es decir, que si un Diputado es nombrado durante el período de su mandato Delegado del Gobierno en una Comunidad Autónoma, no viene obligado a dimitir de ninguno de los dos cargos, ya que ambos son compatibles y no hay, por tanto, causa de incompatibilidad. Sin embargo, el ser titular del cargo de Delegado del Gobierno sí produce una causa de inelegibilidad, esto es, el titular de dicho cargo no podrá ser elegido Diputado al Congreso mientras no dimita del mismo.

Entendemos que conforme a este criterio, se resuelve el problema mencionado atendiendo al régimen jurídico de incompatibilidades, al que han de someterse los Diputados al Congreso. Sin embargo, y habida cuenta de que la Administración ejerce, conforme establece el artículo 97 de la Constitución, la potestad reglamentaria, de acuerdo con la Constitución y las leyes, nada parece impedir que, en tanto no vulnere el principio de jerarquía normativa, pueda 
dictar reglamentos por los que se establezca el régimen jurídico de incompatibilidades, al que han de someterse sus miembros. Creemos que es éste el caso que aquí se plantea, por lo que parece claro que los Delegados del Gobierno han de regirse, en lo referente al régimen de incompatibilidades de su cargo, conforme a lo dispuesto en el Real Decreto 2238/1980, con independencia de que deban someterse también al régimen de incompatibilidades establecido para los Diputados, en el caso de que ostenten además dicho cargo. En este sentido, del tenor literal del artículo $3 .^{\circ}, 1$, del citado Real Decreto, «el Gobernador general no podrá ejercer ninguna función pública que no derive de su cargo", no parece que pueda ejercer la función de Diputado.

Por otra parte, conforme establece el último inciso de este mismo artículo, el ejercicio del cargo de Delegado del Gobierno es incompatible no sólo con el ejercicio de cualquier actividad profesional o mercantil dentro del territorio de la Comunidad Autónoma, sino también con el ejercicio de cualquiera de esas actividades fuera de dicho ámbito territorial. Puede compararse este precepto con el del artículo 9. ${ }^{\circ}$ del Real Decreto 3117/1980, regulador del nuevo Estatuto de los Gobernadores civiles, que dice: «el cargo de Gobernador civil es incompatible con el ejercicio de cualquier otro de carácter público y, dentro de la Provincia, con toda clase de profesiones o actividades mercantiles o industriales».

En caso de ausencia, vacante o enfermedad, el Delegado del Gobierno será sustituido por el Gobernador civil de la Provincia donde aquél tenga su sede y, en su defecto, por el Gobernador civil más antiguo de las Provincias comprendidas en el territorio de la Comunidad Autónoma, conforme establece el artículo $4 .^{\circ}, 2$, del Real Decreto 2238/1980. Ahora bien, es necesario hacer una observación, y es que este precepto es inaplicable a los supuestos en que se produzca la ausencia, vacante o enfermedad del Delegado del Gobierno en Comunidades Autónomas cuyo ámbito no exceda de una Provincia, puesto que en estas Comunidades el Delegado del Gobierno asumirá las competencias propias del Gobernador civil, conforme dispone el artículo 12 del mismo Real Decreto, lo que parece necesariamente implicar la supresión en dichas Comunidades de la figura del Gobernador civil.

Otro aspecto del Estatuto personal de los Delegados del Gobierno en las Comunidades Autónomas es el referente al deber de residencia de los mismos. En el anteproyecto elaborado por la ponen- 
cia constitucional se establecía la obligación de residencia del Delegado del Gobierno en la capital de la Comunidad Autónoma, pero esta obligación fue suprimida después por la propia ponencia constitucional. El artículo $4 .^{\circ}, 1$, del Real Decreto 2238/1980, dice que «el Gobernador general tendrá su sede en la misma localidad donde la tenga el Consejo del Gobierno de la Comunidad Autónoma», por lo que vendrá obligado a residir en dicha localidad, si se está a lo establecido en el artículo 77, 1, de la Ley de Funcionarios Civiles del Estado, de 7 de febrero de 1964, que dice: «los funcionarios deberán residir en el término municipal donde radique la oficina, dependencia o lugar donde presten sus servicios".

La materia de la responsabilidad del Delegado del Gobierno por actos cometidos en el ejercicio de su cargo, se regula en el artículo 3. ${ }^{\circ}, 2$, del Real Decreto 2238/1980, que dice: «la responsabilidad civil y penal del Gobernador general por los actos realizados en el ejercicio de sus funciones o con ocasión de las mismas, será exigible ante la Sala competente del Tribunal Supremo, de acuerdo con lo previsto en la Ley de Régimen Jurídico de la Administración del Estado".

El artículo 11 del Real Decreto 2238/1980 establece, en su primer párrafo, que los Delegados del Gobierno recibirán, a través de la Presidencia del Gobierno, las instrucciones de carácter general precisas para el ejercicio de sus funciones, y añade en el párrafo segundo, que asimismo mantendrán la comunicación necesaria con los Departamentos ministeriales, a los que podrán elevar informe sobre las cuestiones de la específica competencia de aquéllos.

Finalmente, en materia de precedencias, el artículo 5. del Real Decreto 2238/1980 otorga al Delegado del Gobierno precedencia en todos los actos oficiales sobre cualquier otra autoridad con jurisdicción en el ámbito de la Comunidad, pero establece una excepción: «salvo que asista el Presidente del Consejo de Gobierno de la Comunidad Autónoma", fundando esta salvedad en que el artículo 152, 1, de la Constitución atribuye al Presidente de la Comunidad la representación ordinaria del Estado en la misma. Puesto que de las funciones representativas nos ocuparemos más adelante, baste indicar aquí la conflictividad que plantea este precepto al atribuir al Delegado del Gobierno precedencia sobre las autoridades propias de la Comunidad Autónoma que no sean el Presidente de la misma. En este sentido, dicho precepto ha venido a ser modificado 
por vía de hecho en lo que se refiere al Presidente del Parlamento de Cataluña.

Por último, en el párrafo tercero de este artículo, se añade que «la precedencia en los actos militares, judiciales y académicos se regirá por sus normas específicas».

\section{COMPETENCIAS}

El artículo 154 de la Constitución atribuye dos funciones al Delegado del Gobierno en las Comunidades Autónomas: a) la dirección de la Administración del Estado en el territorio de la Comunidad Autónoma, y b) la coordinación, cuando proceda, de la Administración del Estado en el territorio de la Comunidad Autónoma con la Administración propia de la Comunidad.

Esta dualidad de funciones se reconoce en el preámbulo del Real Decreto 2238/1980, donde se dice que el adecuado desarrollo del artículo 154 de la Constitución exige regular, «de una parte, el marco de actuación del Delegado del Gobierno, en su carácter de autoridad superior de los órganos de la Administración Periférica Civil e Institucional del Estado en el respectivo territorio y, de otra, los cauces por los que ha de ejercer su función de coordinar la acción de la Administración del Estado con la propia de la Comunidad Autónoma».

Analizaremos a continuación, por tanto, las competencias que atribuye a los Delegados del Gobierno el Real Decreto que los regula, en relación con el ejercicio de cada una de las dos funciones enumeradas.

\section{a) Dirección de la Administración del Estado en el territorio de la Comunidad Autónoma}

Dice el artículo $5^{\circ}, 1$, del Real Decreto 2238/1980, que el Delegado del Gobierno «ejerce su superior autoridad sobre todos los órganos de la Administración civil del Estado en el territorio de la Comunidad».

En las Comunidades Autónomas cuyo ámbito territorial no exceda de una Provincia, el Delegado del Gobierno asumirá las competencias propias del Gobernador civil, conforme se dispone en el artículo 12 del mismo Real Decreto. Ahora bien, conviene hacer una 
precisión, y es que este precepto parece hacer equivaler los supuestos de Comunidades cuyo ámbito territorial no supere el de una Provincia, con aquellos otros de Comunidades Autónomas uniprovinciales, es decir, de Comunidades cuyo ámbito territorial coincida con el de una Provincia. Sin embargo, dichos supuestos son distintos, puesto que los territorios cuyo ámbito no supere el de una Provincia, a los que se reconoce el derecho a la autonomía en los términos del artículo 144, a), de la Constitución, pueden tener una extensión inferior a la de una Provincia. En este caso, tanto si antes de constituirse en Comunidades Autónomas dichos territorios formaban parte de una Provincia como si no, caso de las ciudades de Ceuta y Melilla, cuyo derecho a la autonomía se reconoce en la disposición transitoria quinta de la Constitución, difícilmente será aplicable a ellos el citado artículo 12 del Real Decreto 2238/ 1980.

Parece, por tanto, que deba interpretarse dicho artículo en el sentido de que al hablar de "Comunidades Autónomas cuyo ámbito no exceda de una Provincia», se pretende designar exclusivamente a las Comunidades uniprovinciales. No obstante, es necesario subrayar que en la práctica pueden plantearse supuestos en que territorios que tengan una extensión inferior a la de una Provincia accedan a la autonomía en la forma prevista en la Constitución, para los cuales no puede ser de aplicación el precepto mencionado.

En las Comunidades Autónomas uniprovinciales, el Delegado del Gobierno, por virtud de lo dispuesto en el artículo 12 del Real Decreto 2238/1980, asumirá, además de aquellas competencias que este Real Decreto atribuye a los demás Delegados del Gobierno, y que citaremos a continuación, las competencias propias del Gobernador civil. Por ello, ejercerá la superior dirección de todos los servicios periféricos de la Administración en la Comunidad (artículo 1.․, párrafo segundo, del Real Decreto 3117/1980), ayudado por la Comisión Provincial de Gobierno, que estará integrada conforme se establece en el Real Decreto 2668/1977, de 15 de octubre (art. 19 del Real Decreto 3117/1980, en relación con el art. 12 del Real Decreto 2238/1980), y asumirá asimismo las demás atribuciones y facultades que se confieren a los Gobernadores civiles en el Real Decreto $3117 / 1980$ (arts. 11 y sigs.).

En los casos de Comunidades Autónomas cuyo ámbito territorial supere el de una Provincia, será aplicable el artículo $6 .^{\circ}, 1$, del Real Decreto 2238/1980, conforme al cual, «el Gobernador general 
ejerce su superior autoridad sobre los Gobernadores civiles de las Provincias comprendidas en la Comunidad Autónoma y, a través de ellos, sobre todos los órganos de la Administración periférica civil del Estado».

En el ejercicio de sus atribuciones, el Delegado del Gobierno contará con la colaboración de una Comisión de Coordinación presidida por él e integrada además por los Gobernadores civiles de las Provincias comprendidas en el territorio de la Comunidad, a cuyas sesiones podrá convocar a los titulares de los órganos y servicios periféricos que estime oportuno (art. 9. del Real Decreto 2238/1980).

En virtud de su carácter de autoridad superior de los órganos de la Administración del Estado en el territorio de la Comunidad Autónoma, corresponden al Delegado del Gobierno las competencias que le atribuyen los artículos 6., 2 , y 8. ${ }^{\circ}$ del Real Decreto 2238/ 1980, que enumeramos seguidamente:

a) Velar por el cumplimiento de las leyes y de las normas reglamentarias del Estado, así como por el de los acuerdos y resoluciones del Gobierno y de los órganos de la Administración civil del Estado, que sean de aplicación en el territorio de la Comunidad Autónoma.

b) Dirigir, impulsar, coordinar e inspeccionar los servicios y organismos autónomos de la Administración civil del Estado en el' ámbito de la Comunidad Autónoma e impartirles, de acuerdo con las directrices del Gobierno, las instrucciones necesarias para ordenar su actividad.

c) Dirigir y coordinar, en los términos previstos en las leyes y a través de los Gobernadores civiles, la actuación de los Cuerpos y Fuerzas de Seguridad del Estado.

d) Conocer e informar las propuestas de nombramiento y cese de los Gobernadores civiles y de los titulares de los órganos y servicios de la Administración periférica civil del Estado correspondientes al ámbito de su jurisdicción.

e) Informar, con carácter previo a su aprobación, los planes y programas de inversiones públicas del Estado en el territorio de la Comunidad, así como impulsar, coordinar y vigilar su ejecución.

f) Ejercer las competencias que puedan ser desconcentradas. o delegadas por el Gobierno o por alguno de sus miembros, de acuerdo con la Ley de Régimen Jurídico de la Administración del Estado. 
g) Ejercer cuantas otras atribuciones le confiera el ordenamiento jurídico estatal (art. 6.․, 2, del Real Decreto 2238/1980).

Asimismo le corresponde al Delegado del Gobierno adoptar las medidas oportunas, en coordinación con los Gobernadores civiles, para preservar el principio de igualdad y proteger el ejercicio de los derechos y libertades públicas de los españoles reconocidos en la Constitución y las leyes (art. 8..$^{\circ}$ del Real Decreto 2238/1980).

El artículo 10 del Real Decreto 2238/1980 dice, en su primer párrafo, que los Gobernadores generales elevarán anualmente un informe al Gobierno sobre el funcionamiento de la Administración del Estado en el ámbito de la Comunidad Autónoma, y añade, en el párrafo segundo, que cuando sean convocados para ello, podrán asistir a las reuniones del Consejo de Ministros para informar a éste.

Corresponden, además, a los Delegados del Gobierno en las Comunidades Autónomas del País Vasco y de Cataluña, por delegación del Ministro competente y sin perjuicio de su superior dirección, las atribuciones previstấs en los números $1,6,7,9,10$ y 11 del artículo 14 de la Ley de Régimen Jurídico de la Administración del Estado respecto de las unidades que se les adscriben, conforme se dispone en los Reales Decretos 3184 y 3185, de 22 de diciembre de 1980.

No se dice, por el contrario, en el Real Decreto por el que se regulan los Delegados del Gobierno en las Comunidades Autónomas, que corresponda a éstos la función de suspender los acuerdos y resoluciones de las autoridades, servicios y organismos del Estado en la Comunidad, ni tampoco la de instruir expedientes disciplinarios y suspender provisionalmente a los funcionarios de la Administración del Estado en el territorio de la Comunidad Autónoma. La primera de estas facultades se atribuye a los Gobernadores civiles en el artículo 11, e), del Real Decreto 3117/1980, en tanto que la facultad sancionadora se atribuye a los mismos en el artículo 17,e), del mismo Real Decreto, respecto de los órganos de la Administración del Estado en la Provincia, por lo que tales facultades deben corresponder a los Delegados del Gobierno en las Comunidades Autónomas uniprovinciales, a tenor de lo que se establece en el artículo 12 del Real Decreto 2238/1980.

En cuanto a las funciones representativas, el Real Decreto 2238/ 1980 establece, en su artículo $5 .^{\circ}, 1$, que «el Gobernador general os- 
tenta la más alta representación del Gobierno en la Comunidad Autónoma».

Este precepto plantea problemas de interpretación, ya que el artículo 152, 1, de la Constitución atribuye al Presidente del Consejo de Gobierno de la Comunidad Autónoma la suprema representación de la respectiva Comunidad y la ordinaria del Estado en aquélla. Igual representación se confiere a los respectivos Presidentes de la Comunidad Autónoma en los Estatutos Vasco, Catalán y Gallego:

El artículo 33, 2, del Estatuto Vasco dice que el Presidente del Gobierno Vasco ostenta, a la vez, la más alta representación del País Vasco y la ordinaria del Estado en este territorio.

En el artículo 36, 2, del Estatuto de Cataluña se dice que el' Presidente de la Generalidad ostenta la más alta representación de la Generalidad y la ordinaria del Estado en Cataluña.

Por último, dice el artículo 15, 1, del Estatuto Gallego que el Presidente de la Junta ostenta la representación de la Comunidad Autónoma y la ordinaria del Estado en Galicia.

Como ha dicho A. González Hernando $\left({ }^{*}\right)$, sería interesante conocer la interpretación dada al artículo 152, 1, de la Constitución. tanto por los parlamentarios como por la doctrina, a fin de ver la posible repercusión del mismo en el ámbito competencial del Delegado del Gobierno y, hemos de añadir nosotros, a fin de conocer la interpretación que deba darse al precepto del artículo $5^{\circ}, 1$, del Real Decreto 2238/1980, antes mencionado. Dicho autor entiende asimismo que las figuras del Delegado del Gobierno y del Presidente del Consejo de Gobierno de la Comunidad Autónoma se mueven en un plano de actuación diferente, de forma que mientras al Delegado del Gobierno le corresponde la representación en el campo puramente administrativo, el Presidente de la Comunidad la ostenta en el ámbito político, todo ello dejando a salvo la representación extraordinaria del Estado, que será asumida por quien sea: designado a tal efecto en cada circunstancia concreta.

Cualquiera que sea, no obstante, la interpretación que se dé a dicho artículo $5^{\circ}, 1$, del Real Decreto $2238 / 1980$, lo que es evidente es que el mismo no puede contradecir lo dispuesto en el artículo 152,1 , de la Constitución ni en los Estatutos Vasco, Catalán y Ga-

(*) A. González Hernando: El Delegado del Gobierno en las Comunidades Autónomas, Madrid, 1980, pág. 45. 
llego, puesto que al tratarse de normas de rango superior, carecería de validez (art. 1, 2, del Código Civil).

También parece claro que dicho precepto atribuye al Delegado del Gobierno una representación distinta a la que se atribuye en la Constitución y los citados Estatutos al Presidente de la Comunidad Autónoma, puesto que los términos «Gobierno» y «Estado» no son equivalentes, sino que, por el contrario, éste es más amplio y comprende, además, al primero. No debe por ello inducir a error el que se diga en aquel precepto «la más alta» representación del Gobierno, y en éstos «la ordinaria» del Estado.

De todo lo expuesto anteriormente relativo a las competencias que corresponden al Delegado del Gobierno para el ejercicio de su función de dirigir la Administración del Estado en el territorio de la Comunidad, pueden extraerse las siguientes conclusiones:

1. Que tanto en el caso de las Comunidades Autónomas uniprovinciales, como en el de las Comunidades pluriprovinciales, la totalidad de la Administración del Estado en el territorio de las mismas debe organizarse jerárquicamente en relación con la figura del Delegado del Gobierno. Igualmente parece que ha de organizarse la Administración del Estado en el territorio de las Comunidades Autónomas cuyo ámbito sea inferior al de una Provincia, aunque, como se ha visto, no las contemple el Real Decreto 2238/ 1980, al menos expresamente.

2. $\quad$ Que se mantiene la Provincia como ámbito territorial básico de actuación de la Administración periférica civil del Estado, es decir, como ámbito de gestión y ejecución de los servicios, reservándose en el supuesto de Comunidades pluriprovinciales, al Delegado del Gobierno las tareas de planificación, coordinación e inspección de aquéllos.

3. Que como consecuencia de lo anterior, en las Comunidades Autónomas pluriprovinciales coexistirán la figura del Delegado del Gobierno y las de los Gobernadores civiles de las Provincias comprendidas en el territorio de la Comunidad, incluso la del Gobernador civil de la Provincia donde tenga su sede el Delegado del Gobierno, como se desprende del artículo $4 .^{\circ}, 2$, del Real Decreto $2238 / 1980$, pese a que razones de economía y eficacia aconsejen lo contrario, habida cuenta que esta superposición de órganos de la Administración civil del Estado se corresponde con una conside- 
rable disminución de las competencias estatales debido a la transferencia de funciones y servicios por parte del Estado a las Comunidades Autónomas.

\section{b) Coordinación, cuando proceda, de la Administración del Estado en el territorio de la Comunidad Autónoma con la Administración propia de la Comunidad}

Durante la Segunda República se adoptó el sistema de comisiones mixtas de coordinación, integradas por representantes de la Administración estatal y de la Administración regional, si bien estas comisiones no tenían carácter general, sino específico, esto es, por materias. Así, la Junta de Seguridad de Cataluña, creada entonces para coordinar las competencias compartidas en materia de orden público, estaba integrada por representantes del Gobierno de la República y de la Generalidad y por las autoridades superiores dependientes de uno y de otra que prestaban servicios en el territorio regional. Los vigentes Estatutos Catalán, Vasco y Gallego crean una Junta de Seguridad semejante, de composición mixta y paritaria.

No es éste, en cambio, el sistema que establece el Real Decreto 2238/1980, que atribuye al Gobernador general, en cuanto Delegado permanente del Gobierno en la Comunidad Autónoma, la función de coordinar la Administración del Estado con la propia de la Comunidad Autónoma en los términos previstos en la Constitución y en los Estatutos de Autonomía (art. $7 .^{\circ}, 1$ ), ya que si bien se crea una Comisión de Coordinación (art. 9..$^{\circ}$ en dicho Real Decreto 2238/ 1980, la misma está integrada exclusivamente por representantes de la Administración estatal.

En el artículo $7 .^{\circ}, 2$, del Real Decreto 2238/1980 se atribuyen al Delegado del Gobierno para el ejercicio de su función de coordinación de la Administración del Estado en el territorio de la Comunidad Autónoma con la propia de la Comunidad, las siguientes competencias:

a) Promover, si procede, el ejercicio de las acciones legales que puedan corresponder a la Administración del Estado para impugnar ante los Tribunales ordinarios y contencioso-administrativos, los acuerdos y disposiciones normativas de rango inferior a las leyes emanados por los órganos de las Comunidades Autónomas.

b) Informar al Gobierno en cuanto al ejercicio por éste de la facultad establecida en el artículo 155, 1, de la Constitución. Este 
precepto constitucional confiere al Gobierno la facultad de adoptar las medidas necesarias para obligar al cumplimiento forzoso de las obligaciones que la Constitución o las leyes impongan a las Comunidades Autónomas, en el caso de que una de éstas las incumpliere, así como para proteger el interés general cuando una Comunidad atente gravemente contra él. Conviene rcordar que en dicho precepto se añade que para el ejercicio por el Gobierno de esta facultad se requiere en todo caso la aprobación por mayoría absoluta del Senado de dichas medidas, previo requerimiento al Presidente de la Comunidad Autónoma que incumpliere sus obligaciones o atentare gravemente contra el interés general.

c) Proponer o informar al Gobierno respecto de la acción de impugnación por éste de las disposiciones y resoluciones adoptadas por los órganos de las Comunidades Autónomas ante el Tribunal Constitucional, prevista en el artículo 161,2, de la Constitución.

d) Instar al Gobierno para el ejercicio de la función prevista en el artículo 153, b), en relación con el artículo 150, 2, de la Constitución. El artículo 150, 2, de la Constitución dice que «el Estado podrá transferir o delegar en las Comunidades Autónomas, mediante ley orgánica, facultades correspondientes a materia de titularidad estatal que por su propia naturaleza sean susceptibles de transferencia o delegación. La ley preverá en cada caso la correspondiente transferencia de medios financieros, así como las formas de control que se reserve el Estado". El artículo 153, b), de la Constitución atribuye al Gobierno, previo dictamen del Consejo de Estado, el control del ejercicio de las funciones delegadas a que se refiere el artículo 150, 2, por parte de los órganos 'de las Comunidades Autónomas.

Es de señalar que es éste el único supuesto en que la Constitución atribuye funciones de control al Gobierno sobre la actividad de los órganos de las Comunidades Autónomas, puesto que en los restantes casos dicho control se atribuye a los Tribunales y que, por tanto, hubiera podido constituir, asimismo, el único supuesto en que el Delegado del Gobierno ejerciera una auténtica función fiscalizadora de los actos de la Comunidad Autónoma. Sin embargo, no se atribuye tal función al Delegado del Gobierno por el Real Decreto $2238 / 1980$, ya que lo único que el mismo puede hacer en este caso es «instar» al Gobierno para que ejercite tal función.

e) Mantener las necesarias relaciones de cooperación entre la Administración del Estado y la de la Comunidad Autónoma, espe- 
cialmente en los supuestos de competencias conjuntas o compartidas $y$, en particular, en los que atañen al ordenamiento general de la economía.

f) Asesorar al Gobierno sobre la transferencia o delegación de funciones y servicios estatales a favor de la Comunidad.

g) Informar regularmente al Gobierno sobre el ejercicio de sus funciones.

h) Cualesquiera otras competencias que se le atribuyan por norma legal o reglamentaria.

De la lectura del precepto transcrito se deduce que lo que en el mismo se atribuye al Delegado del Gobierno en las Comunidades Autónomas no es tal función de coordinación, sino una mera función de vigilancia de las infracciones legales que puedan cometer las Comunidades, puesto que, en definitiva, quienes controlan la actividad de las Comunidades Autónomas son los Tribunales, ya sea el Tribunal Constitucional, ya los Tribunales ordinarios o contencioso-administrativos. Tampoco se le atribuye tal función en el supuesto antes mencionado del ejercicio por los órganos de las Comunidades Autónomas de las funciones delegadas por el Estado, puesto que en este caso el Gobierno se reserva dicha función. Es de observar, además, que la Constitución ni siquiera legitima activamente al Delegado del Gobierno para interponer recurso de inconstitucionalidad.

Puede, por tanto, concluirse que el Delegado del Gobierno no goza de un verdadero poder de coordinación, puesto que éste es inherente a la potestad jerárquica, y si bien aquél goza de esta potestad respecto de los órganos de la Administración del Estado en el territorio de la Comunidad Autónoma, carece de ella respecto de los órganos de la Administración propia de la Comunidad. Lo anterior es consecuencia de la atribución de funciones de su exclusiva competencia a las Comunidades Autónomas por la propia Constitución (art. 148), hecho que parece estar en contradicción con el empleo del verbo "coordinar» en el artículo 154, ya que para coordinar dos Administraciones es preciso tener un poder superior a ambas. 